\section{Dezesseis anos do plano diretor de reforma do aparelho do estado (PDRAE): introdução à análise crítica sobre o papel do Estado brasileiro contemporâneo*}

\section{Sixteen-year master plan for the reform of state apparatus (pdrae): introduction to critical analysis on the role of contemporary brazilian State}

Bianca Tomaino de Souza ${ }^{1}$

\section{Resumo}

O presente trabalho visa a estabelecer breve análise acerca da evolução das Organizações Sociais Civis como elemento susbstitutivo das atribuições do Estado contemporâneo. A Reforma do Aparelho do Estado Brasileiro consolidou-se como medida encontrada pela Administração Pública visando a solucionar problemas de ordem social, política e econômica, cujos sintomas eclodiram na década de 1970, mediante a chamada crise endógena do Estado. Ressalta-se, ainda, que a participação democrática como fundamento da Reforma do Aparelho do Estado encontra óbice na própria noção contemporânea de sociedade civil, sobretudo a sociedade civil brasileira, em razão de características inerentes à trajetória de sua formação. Foi necessário dedicar especial atenção ao contexto brasileiro, através de metodologia pluridisciplinar, estabelecendo o diálogo acadêmico entre campos de conhecimento distintos, como o Direito e a Ciência Política. A análise documental, como empreendimento empírico, também se faz necessária para compreender o fenômeno normativo conformado em nova estratégia de gestão do Estado Nacional, sob o compromisso da eficácia e respaldada pela atual Constituição Federal. Quando da redação do Plano Diretor de Reforma do Aparelho Estatal (PDRAE), muitos dos argumentos foram direcionados à forma incipiente como o Estado administrou tanto a economia como a prestação dos serviços públicos. Frise-se, ainda, que o documento que formaliza a reorganização administrativa do Estado Brasileiro, PDRAE, apenas indicou tarefas à sociedade civil, mediante a criação de organizações sociais, regulamentadas por lei, sem, contudo, imputar a si mesmo obrigações para auxiliar na prestação de serviços públicos historicamente de responsabilidade estatal.

Palavras-chave: Direito. Sociedade Civil. Reforma do Estado.

\section{Abstract}

The present paper aims to establish brief analysis about the evolution of Social Organizations of Civil replacement assignments as part of the contemporary state. The reform of the Brazilian State has established itself as the measure found by the public in order to solve social problems, political and economic, symptoms of which broke out in the seventies, through the
Artigo recebido em 15/11/2011

Artigo aprovado em 20/05/2012

Mestre em Direito pela Universidade Federal do Rio de Janeiro (UFRJ). Bacharel em Direito pela Universidade do Estado do Rio de Janeiro (UERJ). Advogada no Rio de Janeiro. 
so-called endogenous crisis of the state. It should be noted also that democratic participation as the foundation of the State Apparatus Reform obstacle lies in the very contemporary notion of civil society, especially the Brazilian civil society, because of the inherent characteristics of the trajectory of their formation. It was necessary to devote special attention to the Brazilian context through multidisciplinary approach, establishing the academic dialogue between different fields of knowledge such as law and political science. The document analysis as an empirical endeavor, it is also necessary to understand the phenomenon of regulatory conformed new strategy for management of the national state, under the promise of effective and backed by the Federal Constitution. When drafting the Master Plan for Reform of the state apparatus (PDRAE), many of the arguments were directed to incipient form as the state administered both the economy and the provision of public services. It should be stressed also that the document that formalizes the administrative reorganization of the Brazilian State, PDRAE only indicated tasks to civil society through the creation of social organizations, regulated by law, without, however, allocate yourself obligations to assist in provision of public services historically a state responsibility.

Keywords: Law. Civil society. State reform.

\section{Introdução}

O presente trabalho visa a estabelecer uma breve análise acerca da evolução das Organizações Sociais Civis como elemento susbstitutivo das atribuições do Estado contemporâneo. Com o foco no Estado brasileiro, busca-se permear a linha condutora da atual conjuntura do tema proposto a partir de uma análise interdisciplinar, a qual, além da ciência jurídica, incorpora elementos e doutrinadores da Sociologia e da Ciência Política, com o intuito de auxiliar a desvendar questões até o presente momento carentes de respostas.

Nas páginas que seguem, verifica-se que as vicissitudes políticas, históricas e econômicas nacionais atingem o auge na segunda metade do século XX, com a denominada crise fiscal do Estado. Assistia-se, nesse momento, à sedimentação do capitalismo como modelo econômico insuperável e suas consequências na realidade social contemporânea: nos anos 80 , a maioria dos países ca, quando começa a se mostrar evidente o irrealismo da proposta neoliberal. Após longo período pós-Segunda Grande Guerra, em que o Estado tomou para si a responsabilidade de prestar condições materiais mínimas de bem estar à população, a pujança econômica chega ao fim, acarretando a volta de um quadro adiado durante o período que variou do final da Segunda Guerra Mundial até meados da década de 1970. Seja nos demais países da América Latina ou no Brasil, especificamente, houve retração da economia e o retorno de quadros sociais indesejáveis, como a violência e pobreza nas ruas, associadas, em contrapartida, a um crescimento demográfico resultante da implementação de novas técnicas científicas que adicionaram bastantes elementos a elevar a qualidade de vida da população. Era o fim da Época de Ouro. ${ }^{2}$

Nesta fase o Brasil permanecia sob o regime ditatorial militar, período em que a ascensão econômica convivia com a supressão de direitos políticos e civis. Ao final da década de 1970 e nos primeiros quatro anos da década de 1980, o país iniciava sua transição política para o retorno da democracia, após mais de vinte anos de ditadura.

A ingerência do Estado brasileiro, agora tido como ineficiente, corrupto e em crise, encontra-se, pois, descartada. A partir dos últimos vinte anos, essa nova visão passa a conviver com a aceitação de uma realidade globalizada, permeada de uma falsa concepção de integração entre povos e distribuição de bens, sejam eles materiais ou imateriais. Juntos, compõem os vértices da ideologia do possibilismo ${ }^{3}$ na qual se refugia o terceiro setor que conta, atualmente, com mais de quinhentas mil organizações, sob as formas de Organizações Não Governamentais (ONGs), fundações, Organização da Sociedade Civil de Interesse Público (OSCIPS), Serviço Social Autônomo; filial, no Brasil, de Fundação ou Associação estrangeira, dentre outras.

O papel exercido atualmente pela sociedade civil, por meio de associações organizadas, é passível de estudo não apenas sob um prisma objetivo, segundo os êxitos e

2 HOBSBAWN. Eric. A era dos extremos: o breve século XX 1914-1991. 2. ed. São Paulo: Companhia das Letras, 2002. p. 345.

3 MONTAÑO, Carlos. Terceiro setor e questão social: crítica ao padrão emergente de intervenção social. 4. ed. São Paulo: Cortez, 2007. p. 115. 
deficiências dos textos normativos que envolvem o tema. Mais do que isso, é necessário abordar questões atinentes ao real papel que as populares ONGs e demais figuras jurídicas associativas exercem, por intermédio de um olhar direcionado às funções originalmente prescritas ao Estado brasileiro, aliando os parâmetros normativos insculpidos na Constituição Federal de 1988 aos traçados histórico e político nacionais.

\section{Crise como justificativa da reforma do Estado brasileiro}

A Reforma do Aparelho do Estado Brasileiro consolidou-se como medida encontrada pela Administração Pública visando a solucionar problemas de ordem social, política e econômica, cujos sintomas eclodiram na década de 1970, mediante a chamada crise endógena do Estado. ${ }^{4}$ Contudo, as deficiências apontadas possuem raízes em períodos antecedentes da história não apenas brasileira como mundial, assumindo contornos conforme as fragilidades estruturais dos Estados atingidos.

Crises e desgastes de modelos administrativos e econômicos sempre acompanharam os Estados-Nação. A partir do século XX, o primeiro grande desafio enfrentado pela comunidade mundial foi o descontentamento com o liberalismo ${ }^{5}$, em fase que Eric Hobsbawm denomina "Era da Catástrofe", na qual compreendia os anos de 1929 a 1933, ${ }^{6}$ após a Primeira Guerra Mundial e a Revolução Russa. Ainda segundo Hobsbawm, ponto marcante daqueles que sobreviveram às vicissitudes das primeiras décadas do século XX reside no choque proporcionado pela visualização da derrocada de valores e instituições do sistema liberal, o qual houvera sido qualificado como base para o progresso industrial e econômico da civilização no século XIX. Ademais, segue o autor, em seu raciocínio, a própria política liberal, fundada nos princípios de livre iniciativa de produção entre particulares, não possibilitava, através dos governos de democracia participativa, as condições necessárias para se sustentar no curso de uma crise, tal qual a percorrida na "Era da Catástrofe", contexto da Grande Depressão dos anos de 1930.7

5 Para Murray N. Rothbard, o liberalismo significava "a liberdade individual em todos os seus aspectos interrelacionados. $\mathrm{Na}$ economia, os impostos deveriam ser drasticamente reduzidos, os controles e as regulações, eliminados, e a energia, a empresa humana e os mercados, liberados para produzir e beneficiar toda a massa de consumidores. Os empreendedores deveriam ser, por fim, livres para competir, produzir, criar. A liberdade pessoal e civil deveriam ser garantidas contra a depredação e a tirania do rei e de seus asseclas. A religião, fonte de sangrentas guerras por séculos, quando diferentes facções lutavam pelo controle do Estado, seria liberada da imposição e interferência estatais, de forma que todas as religiões - ou não-religiões - pudessem coexistir em paz. A paz, inclusive, era a política externa do liberalismo clássico; a velha política imperial de engrandecimento do Estado, em busca de poder e riqueza, deveria ser substituída por uma política estrangeira de paz e livre comércio com todas as nações. E, uma vez que a guerra era engendrada por exércitos e marinhas permanentes, pelo poder militar em busca de expansão, esses establishments militares deveriam ser substituídos por milícias locais voluntárias, por cidadãos-civis que apenas desejariam lutar em defesa de seus lares e comunidades particulares [...].O Estado, em suma, deveria ser mantido extremamente pequeno, com um orçamento muito baixo, quase insignificante. Os liberais clássicos nunca desenvolveram uma teoria da taxação, mas todo aumento de impostos era combatido fervorosamente - na América, dois aumentos de impostos foram a faísca que desencadeou, ou quase, a Revolução (o imposto sobre os selos e o imposto sobre o chá). A herança libertária: A Revolução Americana e o liberalismo clássico.

6 HOBSBAWN. Eric. A era dos extremos: o breve século XX 19141991. 2. ed. São Paulo: Companhia das Letras, 2002. p. 360.

7 HOBSBAWN. Eric. A era dos extremos: o breve século XX 1914-1991. 2. ed. São Paulo: Companhia das Letras, 2002. p. 360. São, ainda, condições necessárias, de acordo com Eric Hobsbawm: o consentimento e legitimidade gerais, ainda que da minoria; certo grau de compatibilidade entre os vários componentes do "povo", cujo voto soberano determinava o governo comum; pouco nível de ingerência dos governos democráticos, ou seja, os mesmos não deveriam governar em demasia .
BRESSER-PEREIRA, Luiz Carlos. Uma interpretação da América Latina: a crise do estado. Novos Estudos CBRAP, São Paulo, v. 37, p. 37-57, nov. 2003. 
O mercado livre e a inexistência de uma política social levaram as economias capitalistas à insuficiência de demanda agregada, ensejando uma crise generalizada que abriu espaço para a emergência do Estado Social-Burocrático, de cunho intervencionista. ${ }^{8} \mathrm{~A}$ despeito de uma base conceitual unificada, fundada na prestação de serviços sociais e disciplinamento através da atuação direta nas atividades econômicas, o Estado Social-Burocrático admitiu nomenclaturas ajustadas aos países nos quais sua ideologia foi implementada. Nos países desenvolvidos, especialmente na Europa, surgiu o Estado de Bem-Estar Social (welfare state), nos países em desenvolvimento, assim como nos soviéticos, foi implementado o Estado Desenvolvimenista e protecionista. ${ }^{9}$ Deu-se início à Época de Ouro, ${ }^{10}$ um fenômeno global, sobretudo nos países desenvolvidos.

A economia mundial assistiu a um desenvolvimento exponencial. Todavia, o aumento da produção de manufaturados, bem como a explosão demográfica dos países do Terceiro Mundo ocorreram de modo paritário ao crescimento da capacidade destrutiva do homem perante o meio ambiente, o qual lhe servia apenas como espaço para seu crescimento individual.

As consequências negativas do Estado Social-Burocrático demandaram novas transformações na atuação estatal. Ao elemento Social conferido ao Estado atribuiu-se o conceito "Democrático", ou seja, tem-se um Estado de Direito, eis que protetor das liberdades individuais e do bem comum, aliado a uma roupagem democrática, caracterizada pela ideia da participação popular no processo político, nas decisões do Governo e no controle da Administração Pública.

Isto porque, aos poucos, a qualidade centralizadora do Estado não comportou a demanda por serviços e condições materiais necessárias ao desenvolvimento de

8 JUCÁ, Maria Carolina Miranda. Crise e reforma do Estado: as bases estruturantes do novo modelo. Jus Navigandi, Teresina, ano 7, n. 61, jan. 2003. Disponível em: <http://jus2.uol. com.br/doutrina/texto.asp?id=3598>. Acesso em: 15 maio 2009.

9 JUCÁ, Maria Carolina Miranda. Crise e reforma do Estado: as bases estruturantes do novo modelo. Jus Navigandi, Teresina, ano 7, n. 61, jan. 2003. Disponível em: <http://jus2.uol. com.br/doutrina/texto.asp?id=3598>. Acesso em: 15 maio 2009.

${ }^{10}$ HOBSBAWN. Eric. A Era dos Extremos: o breve século XX 1914-1991. 2. ed. São Paulo: Companhia das Letras, 2002. p. 410. uma população cujo crescimento era cada vez mais pungente. E essa população, maior em número e em expectativa de vida, graças ao advento de relevantes empreendimentos científicos, passara a ser um dos focos de atenção das ações governamentais. O fim da Segunda Grande Guerra foi o estopim para que as constituições apontassem a dignidade da pessoa humana como princípio diretor dos atos protagonizados não apenas entre Poder Público e subordinados, mas também entre particulares. Tal princípio passa a ser o trunfo dos chamados hipossuficientes, nomenclatura utilizada pelo Código de Defesa do Consumidor Brasileiro (Lei no 8.078/90) para designar aqueles em posição de desfavorecimento diante das grandes empresas e conglomerados surgidos principalmente na segunda metade do século XX.

O retrato desenhado pelo Estado Social-Burocrático buscou levar aos indivíduos a nítida sensação de proteção pelo poder público central. Entretanto, sabe-se que nas entrelinhas dos milagres econômicos atingidos, sobretudo nos países em desenvolvimento, governos repressores se estabeleceram, suplantando direitos políticos e civis. Restringindo as manifestações da sociedade civil, assegurava-se o campo para a manutenção de práticas tradicionais dos países subdesenvolvidos, tais como o favorecimento de apadrinhados, o poderio de grandes proprietários, além do corporativismo entre as classes militares, por exemplo. Assim, muito embora o Estado Social-Burocrático fosse o caminho encontrado para fazer frente às lacunas apontadas pelo Liberalismo, o mesmo trouxe consigo os problemas do burocratismo, o qual, por meio da formalidade, deveria servir como meio de tornar as prestações de serviços estatais impessoais aos beneficiados. ${ }^{11}$

Frise-se que a toda solução propagada é preciso haver competência para torná-la eficaz, para colocá-la em prática. Nos argumentos apresentados pelo Plano Diretor de Reforma do Aparelho do Estado de 1995, a governança, enquanto otimização das atribuições governamentais,

\footnotetext{
${ }^{11}$ BRESSER-PEREIRA, Luiz Carlos; NURIA Cunill Grau. Entre o Estado e o Mercado: o público não-estatal. In BRESSER-PEREIRA, L. C; NURIA Cunill Grau (Org.). O público não-estatal na reforma do Estado. Rio de Janeiro: FGV, 1999. p. 109.
} 
se fez bandeira de um novo paradigma de Administração, com ênfase na eficiência e na busca de resultados. ${ }^{12}$

Resultados estes que não eram observados no gigantismo notado junto aos Estados intervencionistas. Para Roberto Ribeiro Bazilli:

Esse gigantismo, em aparente contradição, leva o Estado intervencionista a se esgotar; sobrecarrega o Estado com tarefas dispensáveis e que são melhores desempenhadas pela iniciativa privada; dificulta a adequada realização das atividades essenciais do Estado; a eficiência diminui bem como acarreta a insuficiência de recursos $[\ldots]{ }^{13}$

Destarte, infere-se que os sintomas da crise diagnosticada na década de 1970 não se manifestaram isoladamente, em um curto período de tempo. Pelo contrário, amadureceram até atingirem nível de saturação para o qual a sociedade pergunta-se até hoje como solucionar.

Carlos Montaño sugere que as justificativas apontadas para a crise fiscal do Estado, como a perda de arrecadação e elevado gasto social sem retorno, convergem à seara do capital e seu uso político e econômico pelos governantes, numa relação de causa e efeito, isto é, a opção de aplicação do erário pela Administração resultou no aumento de custos ou inchaço da máquina administrativa. E as escolhas de investimentos circundavam vendas subvencionadas de empresas estatais, renúncia fiscal, hiperfaturamento de obras, resgate de empresas falidas, clientelismo político, corrupção, compras superavaliadas, empréstimos ao capital produtivo com juros corroídos pela inflação, dentre outras. ${ }^{14}$

${ }^{12}$ BRASIL. Plano Diretor de Reforma do Aparelho do Estado - PDRAE. Disponível em: <http://www.planalto.gov.br/ publi_04/colecao/plandi.htm $>$. Acesso em 15 de maio de 2009.

${ }^{13}$ BAZILLI, Roberto Ribeiro. Organizações da Sociedade Civil de Interesse Público: Nova Modalidade de Parceria. Revista dos Tribunais, São Paulo, v. 779, p. 79-92, set. 2000. p. 82 Embora não nos pareça, com todo o respeito ao eminente doutrinador, a melhor posição adotada pelo Estado, é certo que a tese de Bazilli se coaduna com a adotada pelo governo do então Presidente Fernando Henrique Cardoso, quando da elaboração do PDRAE.

${ }^{14}$ MONTAÑO, Carlos. Políticas sociais estatais e "Terceiro Setor": o projeto neoliberal para a atual resposta à "questão social”.I Coloquio Brasil/Uruguay: "Questão urbana, políticas sociais e serviço social”. Escola de Serviço Social - UFRJ. Rio de Janeiro, 11-12 Abril 2002.

\section{Ainda segundo Montaño:}

Particularmente no que se refere à intervenção estatal no financiamento público daquelas áreas fundamentais para a acumulação de capital e para dar respostas às demandas dos trabalhadores organizados, ela aparece como extremamente deficitária; a participação do Estado no financiamento das políticas públicas de interesse econômico ou social, teve em parte de ser financiada com a elevação da carga tributária. Assim, a forma de sustentar os elevados custos de um Estado de Bem-Estar foi por meio da contribuição operária, mediante a taxação ao salário e, em algum grau, empresarial, taxando o lucro [...], o que significou custo extra para o capital. [...]. Com isso, a maior socialização dos custos de capital gerou mais despesas sociais do Estado, o que tendeu à constante elevação dos impostos. Porém, a impossibilidade de aumentá-los indefinidamente levou o Estado a gastar mais do que arrecadava; criou-se, assim, um hiato fiscal. ${ }^{15}$

Eric Hobsbawm, por sua vez, nos lembra que nos vinte anos após o início da década de 1970 o mundo perde suas referências. A incredulidade diante do novo contexto se perfazia numa atmosfera de negação do desmoronamento das fundações da "Época de Ouro". Não houve reconhecimento da natureza global da crise, restando aos problemas econômicos a denominação restrita de recessão. A maioria dos políticos, economistas e homens de negócios não admitia que os efeitos colaterais dos investimentos aplicáveis aos recursos públicos tivessem transformado em caráter permanente a conjuntura econômica da época. Baseavam-se, os mesmos, na concepção de que a crise e seus inúmeros problemas não passavam de intempéries. $^{16}$

Nesse contexto de espanto e incertezas o Brasil iniciava seu processo de abertura política. O país, no final da década de 1970, vivia sob administração do Governo Militar, o qual, como já pronunciado, comprometeu-se com o autoritarismo e supressão dos direitos políticos e civis. Em verdade, apesar de formalizada apenas em 1985, através da eleição do candidato à Presidência Tancredo Neves, a volta da democracia ao Brasil iniciou caminhada

${ }^{15}$ MONTAÑO, Carlos. Políticas sociais estatais e "Terceiro Setor": o projeto neoliberal para a atual resposta à "questão social”.I Coloquio Brasil/Uruguay: "Questão urbana, políticas sociais e serviço social”. Escola de Serviço Social - UFRJ. Rio de Janeiro, 11-12 Abril 2002. p. 217

${ }^{16}$ HOBSBAWN. Eric. A Era dos extremos: o breve século XX 1914-1991. 2. ed. São Paulo: Companhia das Letras, 2002. p.412. 
desde a eleição de Ernesto Geisel, em 1974, que adotou medidas significativas para a abertura política, culminando no fim dos anos de chumbo.

Na passagem dos anos 60 para os 70, o déficit fiscal do Estado brasileiro torna-se verdadeiramente insustentável, deslanchando uma profunda crise fiscal entre 70-80, em decorrência dos argumentos apresentados até aqui. Reafirma-se que o Brasil não escapou da tradição dos países em desenvolvimento. Pelo contrário. $\mathrm{Na}$ década de 1980 o Brasil era considerado forte candidato a campeão mundial em desigualdade econômica, perdendo o posto apenas para pequenos países das Américas. ${ }^{17}$

A definição pelo PDRAE de um Estado Burocrático e paternalista, principalmente a partir da Constituição de 1988, encerraria a crise nacional na esfera burocrática da administração, fato este que corroboraria a tese de crise de governança como o principal elemento justificador da Reforma do Aparelho Estatal. Contudo, confirma-se a razoabilidade do entendimento de Montaño, no sentido de que o problema de o Estado ser excessivamente voltado para interesses privados, via "patrimonialismo" e "clientelismo", deve ser efetivamente combatido com seu contrário, a "desprivatização", e não com a maior "privatização" encoberta em publicização, tornando rarefeitos direitos fundamentais cuja efetivação incipiente nunca fez jus à denominação de Estado protetor, "paternalista" ou "pai dos pobres". 18

\subsection{A crise econômica latino americana e sua relação com a crise brasileira}

A tensão econômica que atingiu o Brasil afetou igualmente a América Latina. A renda per capta dos países reduziu-se em 10\%, acompanhada de crescimento significativo das taxas de inflação. A crise fiscal do Estado possuiu causas básica e suplementar. A primeira corresponde à falência estatal, perda de crédito e imobilização. A segunda vincula-se a um inchaço do Estado, no que toca à política de substituição de importações e intervenções no setor produtivo da economia. ${ }^{19}$

${ }^{17}$ HOBSBAWN. Eric. A Era dos extremos: o breve século XX 1914-1991. 2. ed. São Paulo: Companhia das Letras, 2002.

${ }^{18}$ Este era o apelido dado à Getúlio Vargas diante da sua popularidade.

${ }^{19}$ BRESSER-PEREIRA, Luiz Carlos. Uma interpretação da América Latina: a crise do Estado. Novos Estudos CBRAP,São Paulo, v. 37, p. 37-57, nov. 2003.
Sob o aspecto técnico, a composição do abatimento Latino Americano ocorreu em virtude: a) déficit orçamentário, b) poupanças públicas negativas ou muito pequenas, c) dívida pública externa e interna excessiva, d) falta de crédito do Estado, refletida na falta de confiança na moeda nacional e nos vencimentos de curto prazo da dívida interna (no Brasil, o mercado "overnight" para as obrigações do Tesouro), e) a falta de credibilidade do governo e sua imobilização, que não deve ser confundida com a falta de crédito do Estado. ${ }^{20}$

O diagnóstico da crise necessita de exame em sentido amplo, pois as ocorrências acima elencadas não constituem um fim em si mesmo. Diante da crise emoldurada por Bresser-Pereira, o Brasil, na década de 1990, não conseguiu organizar suas finanças e retomar seu desenvolvimento, enquanto os demais Estados da América Latina paulatinamente ascenderam à recuperação econômica.

A Constituição de 1988 já vigia e o Brasil não vislumbrava perspectiva aos investimentos proclamados como direitos fundamentais da República. O registro na nova Carta dos anseios e traumas decorrentes dos anos de repressão era concomitante à inviabilidade para pô-los em prática, dadas as circunstâncias objetivas da época. Mais do que isso, pode-se questionar até que ponto a própria história calcada no compromisso com o clientelismo e administração incipiente reforçou as consequências e ratificou a qualidade endógena da crise.

\subsubsection{A Globalização como contribuição à crise}

Simultaneamente, o fenômeno da globalização se fazia cada vez mais presente em fins do século XX. De acordo com Alessandro André Leme, "O processo de globalização refere-se a acontecimentos e efeitos globais ou mundiais que se expressam por meio de representações simbólicas, de fabulações, de processos tecnológicos da informação, da integração de mercados, ou dos fluxos econômicos." ${ }^{21}$ Como conceito sociológico ou categoria utilizada pelas ciências sociais para entendimento dos novos processos e formas de organização das relações so-

\footnotetext{
${ }^{20}$ BRESSER-PEREIRA, Luiz Carlos. Uma interpretação da América Latina: a crise do Estado. Novos Estudos CBRAP,São Paulo, v. 37, p. 42, nov. 2003.

${ }^{21}$ BRESSER-PEREIRA, Luiz Carlos. Uma interpretação da América Latina: a crise do Estado. Novos Estudos CBRAP, São Paulo, v. 37, p. 37-57, nov. 2003.
} 
ciais em esfera mundial, a globalização é bastante recente, podendo ser datada nos anos de 1980 e 1990,embora seu início remonte ao século XIX, fase do desenvolvimento mundial em que a ascensão da indústria aponta a tecnologia como elemento transformador definitivo do cotidiano.

No ser humano, a globalização expandiu o comportamento mecânico de conduta das fábricas para as relações subjetivas, onde o homem volta-se ao atingimento das finalidades que lhes são convenientes, em um contexto individualista de isolamento. Afirma Guilherme Massaú que:

[...] cada indivíduo ocupa seu lugar e realiza suas tarefas (in) diferentemente dos demais, no entanto, há um padrão aceitável de convivência e de tolerabilidade; se, por acaso, alguém não consegue atingir esse padrão, é deslocado para a periferia do sistema estabelecendo-se numa espécie de ostracismo; logo com o direito funcionalizado. ${ }^{22}$

Uma organização administrativa saudável seria necessária para assegurar estabilidade ao Estado diante dos efeitos políticos não apenas da globalização no Estado de Direito, como também da globalização das relações sociais e materiais, que exigem integração e interdependência nos planos jurídico, cultural e político. ${ }^{23}$ Isto porque o Estado necessita de maior governança e legitimação junto à sociedade, a fim de evitar a restrição de seu poder decisório enquanto Estado-Nacional. Em se tratando do contexto brasileiro, os governos foram obrigados a elevar taxas de juros, adotar medidas fiscais restritivas e implementar ousadas metas inflacionárias. Consequentemente, houve redução da atividade econômica, elevação do índice de desemprego, queda dos níveis salariais e aumento da pobreza e violência.

Assim, a renovação da institucionalidade política aflora como tema dos estudos praticados à condução da democracia contemporânea, a partir dos anos 90 , cuja base encontra-se firmada em dois planos: a accountability, termo de origem inglesa utilizado para representar "[...]

${ }^{22}$ BRESSER-PEREIRA, Luiz Carlos. Uma interpretação da América Latina: a crise do Estado. Novos Estudos CBRAP,São Paulo, v. 37, p. 42, nov. 2003.

${ }^{23}$ FÊU, Carlos Henrique. Controle interno na Administração Pública: um eficaz instrumento de accountability. Jus Navigandi, Teresina, ano 7, n. 61, jan. 2003. Disponível em:<http:// jus2.uol.com.br/doutrina/texto.asp?id=3598>. Acesso em: 15 maio 2009. a obrigação que a organização tem de prestar contas dos resultados obtidos, em função das responsabilidades que decorrem de uma delegação de poder," ${ }^{24}$ como demanda expressa sobre as instituições públicas, e a cidadania como sujeito político direto, indo além de sua expressão por meio do voto ${ }^{25}$, culminando na emergente atenção à "democracia participativa". ${ }^{26}$

Segundo Marco Aurélio Nogueira, a democracia participativa ou cidadania ativa é uma condição essencialmente política, ou seja, seus protagonistas concebem o mundo como um ambiente de direitos e responsabilidades recíprocas e nele se realizam como sujeitos de vontade e ação coletivamente construídos. ${ }^{27}$ Pondera o autor que a fruição dos direitos, no caso, depende da junção de dois fatores: a inserção de grupos de indivíduos em circunstâncias estatais concretas, aliada a providências governamentais. Tal medida vigora para todas as espécies de direitos, mas principalmente para os direitos sociais. Este raciocínio é conferido à idéia de valorização da política pela sociedade civil, o que não ocorreu no Brasil quando da reforma do aparelho estatal.

${ }^{24}$ FÊU, Carlos Henrique. Controle interno na Administração Pública: um eficaz instrumento de accountability. Jus Navigandi, Teresina, ano 7, n. 61, jan. 2003. Disponível em:<http:// jus2.uol.com.br/doutrina/texto.asp?id=3598>. Acesso em: 15 maio 2009. Segundo o mesmo autor, temos que a accountability aplicada à visão de Administração Pública, "está diretamente ligada à descentralização de responsabilidades, atribuindo poder à base da administração, à sociedade organizada em empresas sem fins lucrativos, tais como associações, cooperativas, organizações não-governamentais, enfim a sociedade civil organizada em busca da cidadania.[...]. A accountability requer o acesso do cidadão à informação e à documentação relativas aos atos públicos, as formas pelas quais seus governantes estão decidindo em seu nome ou gastando o dinheiro que lhes foi entregue sob forma de tributos, portanto, a qualidade da democracia praticada na sociedade depende o grau de transparência das ações governamentais".

${ }^{25}$ Nesse sentido o texto de Marcos Martins sobre a catarse do conceito de cidadania, indo além das noções simples e complexa fundada no direito a voto, também expostas nesse trabalho. De acordo com Martins, a cidadania passa a mediar questões histórico-sociais, só podendo ser entendida como direito (direito e noção psíquica do indivíduo que só vê cidadão pelo exercício de seus direitos e deveres) simultaneamente à posse dos bens que os direitos abstratamente atribuem à pessoa.

${ }^{26}$ BRESSER-PEREIRA. Sociedade Civil: sua democratização para a reforma do Estado. In: BRESSER-PEREIRA, Luis Carlos, WILHEIM, Jorge; SOLA, Lourdes. (Org.). Sociedade e Estado em transformação. São Paulo: UNESP/ENAP, 1999. p. 67-116.

${ }^{27}$ NOGUEIRA, Marco Aurélio. Reforma do Estado e Fortalecimento da Democracia. Disponível em: <http://www.nuso.org/ upload/estado/nogueira.pdf.> Acesso em 29 mar. 2009. 
O movimento reformador não se preocupou em articular sua dinâmica racional-legal com uma dinâmica de emancipação, aberta para a democracia política, a promoção social e a cidadania. Disso deriva a razão maior de seu fracasso. [...] Com isso, em que pesem todos os esforços e toda a movimentação reformadora registrada ao longo dos anos 90 , não se conseguiu passar, na maioria dos países -Brasil incluído-, da "primeira» para a "segunda geração» de reformas do Estado. Ainda que o discurso dominante tenha buscado se distinguir do reformismo neoliberal típico da primeira geração, sua agenda de reformas não construirá uma identidade própria. Ficou-se muito mais próximo de um aprofundamento - em alguns momentos, radicalizado e ideologizado - dos pressupostos do reformismo neoliberal dos anos 80 , concentrando-se na substituição do Estado pelo mercado, no ajuste fiscal e na desregulação da atividade econômica. Em vez de construir um novo Estado, como prevê a agenda da segunda geração, a reforma estacionou nos limites da propalada desconstrução neoliberal do Estado, dedicando-se a desenhar uma imagem negativa do fenômeno estatal e a conceber a reforma como uma operação para comprimir o Estado, não para melhorá-lo. ${ }^{28}$

Ressalta-se, ainda, que a participação democrática como fundamento da Reforma do Aparelho do Estado encontra óbice na própria noção contemporânea de sociedade civil, sobretudo a sociedade civil brasileira, em razão de características inerentes à trajetória de sua formação. A sociedade contemporânea vista atualmente movimenta-se de modo a submeter o esquema jurídico para atingir metas incertas, residentes nas necessidades espontâneas e voluntárias de cada um. Ao direito, por sua vez, compete a função de ressaltar os direitos individuais, afastando-se das obrigações que os acompanham. Logo, observando simultaneamente o comportamento da sociedade com a evolução técnica que a mesma é capaz de produzir, é possível inferir que a valoração progressiva dos direitos em detrimento dos deveres concorre com a velocidade que tanto a industrialização quanto as consequências do desenvolvimento da ciência provocaram por sua invasão no mundo atual, sem que se implementasse, conjuntamente, educação quanto à consciência dos avanços

${ }^{28}$ NOGUEIRA, Marco Aurélio. Reforma do Estado e fortalecimento da democracia. Disponível em: <http://www.nuso.org/ upload/estado/nogueira.pdf.> Acesso em 29 mar. 2009. p. 31. tecnológicos e seus reflexos na imposição da técnica sobre o humano. ${ }^{29}$

Atualmente o Estado não admite o aparelho burocrático como no recém superado Estado Providência ou Estado de Bem-Estar Social. O novo comportamento da Administração Pública observado hoje em dia torna mais intensa a problemática da diferenciação entre Estado e Sociedade Civil, público e privado, indivíduo e cidadão. A Lei, ou melhor, o direito, formaliza o controle estatal, de modo a fazer com que as instituições civis sejam arregimentadas para suprir lacunas deixadas pelo Estado em setores nos quais sua omissão é latente.

\subsubsection{0 início do processo de desestatização no Brasil}

$\mathrm{Na}$ década de 1990, o sinal contundente do plano brasileiro de distanciamento das funções constitucionalmente atribuídas ocorreu com o Programa Nacional de Desestatização, previsto na Lei $n^{\circ} 8.031 / 90$, durante o governo do Presidente Fernando Collor de Mello. Pouco tempo após a promulgação da referida norma, o então presidente é afastado do cargo. Com isso, a discussão acerca das mudanças às novas diretrizes aplicáveis à Administração Pública foi novamente alavancada com o Plano Diretor de Reforma do Aparelho do Estado (PDRAE) de 1995, sob o governo de Fernando Henrique Cardoso. Em sequência, a Lei no 9.491/97 revogou o texto de 1990, assumindo como corolário o reordenamento da posição estratégica do Estado na economia, transferindo à iniciativa privada atividades indevidamente exploradas pelo setor público (art. $\left.1^{\circ}, \mathrm{I}\right)$.

Nos anos 90, a economia brasileira passava pela transição do modelo fechado dos últimos 40 anos para uma concepção de administração econômica mais aberta, mediante a redução de barreiras de importações, desregulamentação do mercado financeiro, além de eliminação de restrições institucionais, visando a maior participação do capital estrangeiro em setores de infraestrutura. ${ }^{30}$ Ao optar por uma industrialização rápida, a fim de se adaptar ao novo ritmo da economia mundial,

${ }^{29}$ MASSAÚ, Guilherme Camargo. A Sociedade do momentâneo: a impossibilidade de fuga para o futuro e o reflexo na senda jurídica. Revista Sociologia Jurídica, n. 4, jan./jun. 2007.

${ }^{30}$ SILBER, Simão David. Mudanças estruturais na economia brasileira (1988-2002): abertura, estabilização e crescimento. Disponível em: <http://www.usp.br/prolam/simao.pdf.> Acesso em: 09 nov. 2008. 
o Brasil passou por dois períodos de transição: o primeiro foi de fechamento da economia, de 1977 a 1988, caracterizado pelo aumento das tarifas de importação e das restrições não tarifárias às importações, o que acabou transformando o país em uma das economias mais fechadas do mundo. A segunda fase iniciou-se em $1988 \mathrm{e}$ se mantém até os dias atuais. A qualificação verificada ao atual contexto econômico nos dá conta de uma abertura da economia fundada no sistema de preços com regras estáveis e acessos aos agentes econômicos. São exemplos de medidas ajustadas à desestatização: acelerar o ritmo de criação, importação e difusão tecnológica, compatível com a expansão da competitividade das empresas brasileiras, tão comprometidas nos anos 80; aumentar a taxa de crescimento do produto, quer por meio da diminuição da restrição externa, quer pela ampliação do mercado externo e interno, dentre outras.

Historicamente, o processo de transição democrática e de desestatização da economia foi caracterizado pela ampla distribuição do poder social a diferentes grupos durante a década de 1980. Isto possibilitou um distanciamento da tradicional centralização política no executivo Federal, a qual acompanhava a adoção do modelo desenvolvimentista desde os anos 30 Segundo Marcus Faro Castro e Maria Isabel Valladão de Carvalho ${ }^{31}$, a consolidação da descentralização do poder do Executivo Federal ocorreu em três fases distintas: a primeira durante e após as eleições diretas de 1982, suplantando o esquema de controle centralizado do executivo central sobre a federação. O segundo passo foi a promulgação da Constituição da República de 1988, incorporando, em seus dispositivos, o princípio de um federalismo mais forte, uma vida política revigorada no legislativo e a chamada judicialização da política. A terceira e última etapa consiste no período compreendido entre 1990 e 1997, mediante o declínio dos movimentos urbanos e ascensão dos movimentos rurais, bem como pela crescente diversidade de interesses e temas, confirmada pela multiplicação de movimentos e associações civis. ${ }^{32}$

${ }^{31}$ CASTRO, Marcus Faro de; CARVALHO, M. I. V. Globalização e transformações políticas recentes no Brasil: os Anos 1990. Revista de Sociologia e Política, Curitiba, v. 18, p. 109129, 2002.

32 CASTRO, Marcus Faro de; CARVAlHO, M. I. V. Globalização e transformações políticas recentes no Brasil: os Anos 1990. Revista de Sociologia e Política, Curitiba, v. 18, p. 109129, 2002.
Deste modo, estava iniciado o processo de redistribuição das tarefas públicas, sob a expectativa da vitória da democracia participativa, da solidariedade, do voluntariado e da união de uma sociedade desigual e reticente em relação à figura de Estado já desgastada ante os acontecimentos envolvendo corrupção e manipulação da máquina administrativa. ${ }^{33}$

\subsubsection{0 plano diretor de reforma do estado (PDRAE)}

O Plano Diretor de Reforma do Aparelho do Estado (PDRAE) foi elaborado pelo Ministério da Administração Federal e da Reforma do Estado. Depois de ampla discussão, foi aprovado pela Câmara da Reforma do Estado, em reunião de 21 de setembro de 1995, para, posteriormente, ser aprovado pelo Presidente da República e implementado, acompanhando tendência desestatizante iniciada no início dos anos 90. De orientação liberal, o PDRAE se apresenta, em suas justificativas, como um novo paradigma de administração pública, com ênfase na busca de resultados em detrimento de uma burocracia excessiva e prejudicial ao cumprimento das finalidades

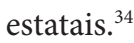

Segundo o plano apresentado, aparelho do Estado ou administração pública lato sensu importa a administração pública em sentido amplo, ou seja, a estrutura organizacional do Estado em seus poderes Executivo, Legislativo e Judiciário, associados às dimensões federativas: Estados, União e Municípios. Constitui-se pelo Governo, por um corpo de funcionários e pela Polícia Militar, regendo-se, principalmente, pelos direitos constitucional e administrativo. Nesse contexto, ao Estado cumpre o papel de fonte ou sancionador não apenas destes, mas de to-

\footnotetext{
${ }^{33}$ Recorde-se que um dos fatores de contribuição para a descrença da sociedade no poder público foram as acusações recaídas sobre o Presidente Fernando Collor de Melo, que culminaram em seu impeachment em 02 de outubro de 1992, ocorrendo posterior julgamento pelo Senado Federal em 29 de outubro de 1992, em sessão presidida pelo Ministro Sydney Sanches, à época presidente do Supremo Tribunal Federal.

${ }^{34}$ No plano estão inseridas variadas informações como defesa à estratégia adotada pelo governo, em 1995. Estatísticas acerca da fragilidade econômica dos cofres públicos, tabelas e gráficos direcionados ao funcionalismo público, objetivos aos setores estatais, etc. Para efeitos práticos, lidaremos prioritariamente com dados que correspondam ao objetivo central deste trabalho, ou seja, a transferência das atribuições que, constitucionalmente, vinculam o Estado aos seus subordinados, mediante obrigações e prestação de direitos ditos fundamentais.
} 
dos os outros direitos, sejam estes civis, políticos, direitos humanos. Logo, o Estado é a única estrutura organizacional que possui o "poder extroverso", ou seja, o poder de constituir unilateralmente obrigações para terceiros, com extravasamento dos seus próprios limites. ${ }^{35}$ Ao contrário da Reforma do Estado, de alcance mais amplo, a Reforma do Aparelho de Estado visa a atingir, prioritariamente, a administração Federal, em nada impedindo que Estados e Municípios a concebam em seus programas de governo.

A redação do Plano Diretor acusa diretamente governos anteriores de se comprometerem com o clientelismo e o patrimonialismo, numa relação causal que imprimiu à administração pública nacional qualidades negativas como o inchaço da máquina administrativa e o compromisso com formalidades excessivas, para depois arguir acerca do retrocesso da Constituição Federal de 1988. A crítica ao documento que teoricamente instituiria as soluções dos percalços democráticos nos quais se envolveu o Brasil nos anos de incipientes direitos políticos e civis encontraria lastro na eventual manutenção da burocracia. Segundo o PDRAE:

A conjunção desses dois fatores leva, na Constituição de 1988, a um retrocesso burocrático sem precedentes. Sem que houvesse maior debate público, o Congresso Constituinte promoveu um surpreendente engessamento do aparelho estatal, ao estender para os serviços do Estado e para as próprias empresas estatais praticamente as mesmas regras burocráticas rígidas adotadas no núcleo estratégico do Estado. A nova Constituição determinou a perda da autonomia do Poder Executivo para tratar da estruturação dos órgãos públicos, instituiu a obrigatoriedade de regime jurídico único para os servidores civis da União, dos Estados-membros e dos Municípios, e retirou da administração indireta a sua flexibilidade operacional, ao atribuir às fundações e autarquias públicas normas de funcionamento idênticas às que regem a administração direta. ${ }^{36}$

O fundamento utilizado no discurso crítico à Constituição de 1988 encontra-se nos projetos de administração experimentados a partir da década de 1930, quando o Estado assume ingerência substancial no setor

\footnotetext{
${ }^{35}$ BRASIL. Plano Diretor de Reforma do Aparelho do Estado - PDRAE. Disponível em: <http://www.planalto.gov.br/publi_04/colecao/plandi.htm>. Acesso em 15 de maio de 2009.

${ }^{36}$ BRASIL. Plano Diretor de Reforma do Aparelho do Estado - PDRAE. Disponível em: <http://www.planalto.gov.br/publi_04/colecao/plandi.htm>. Acesso em 15 de maio de 2009. p. 21
}

de bens e serviços. Em 1936, com o objetivo de modernizar a gestão administrativa no país, foi criado o DASP - Departamento Administrativo do Serviço Público. A relevância do recém criado departamento reside nas tentativas de se atribuir ao Estado brasileiro instrumentos de administração com ênfase no mérito de seus agentes, por meio de concurso público, bem como à equalização e isonomia quando da aquisição de materiais, utilizando-se, para tanto, revisão de estruturas e aplicação de novos métodos de procedimento.

Todavia, como admitido pelo próprio governo, a iniciativa cedeu lugar à manutenção do coronelismo, culminando em sucessivas reformas posteriores, a fim de alcançar objetivo que não mais se qualificava como inovação técnica, mas passara a ser uma necessidade diante de um país cujas dimensões demográficas se faziam cada vez mais amplas e os contornos geográficos cada vez mais evidentes.

Instituídos atos no sentido de minimizar a burocracia administrativa, criadas comissões a exemplo da Comissão de Simplificação Burocrática e da Comissão de Estudos e Projetos Administrativos, em 1967, a promulgação do Decreto-Lei 200 implicou, na esfera normativa, um passo adiante na tentativa de superação da rigidez burocrática. ${ }^{37}$ Mediante o referido Decreto-lei, promoveu-se a transferência de atividades estatais para autarquias, fundações, empresas públicas e sociedades de economia mista, a fim de se obter maior dinamismo operacional por meio da descentralização funcional. Instituíram-se, como princípios de racionalidade administrativa, o planejamento e o orçamento, o descongestionamento das chefias executivas superiores (desconcentração/descentralização), a tentativa de reunir competência e informação no processo decisório, a sistematização, a coordenação e o controle. Um dos princípios fundamentais prescritos no Decreto-Lei 200/67 é a descentralização das atividades públicas, ponto chave para a atual transferência das funções estatais instituída pelo PDRAE, em parceria com as contemporâneas organizações sociais civis. Assim afirmou o Decreto-Lei 200:

\footnotetext{
${ }^{37}$ A descentralização da Administração Pública é um dos princípios contidos no Decreto-Lei200/67, assim como o planejamento, coordenação, controle e delegação de competência. Tais fundamentos estão previstos no art. $6^{\circ}$ da norma em comento.
} 
Capítulo III

\section{DA DESCENTRALIZAÇÃO}

Art. 10. A execução das atividades da Administração Federal deverá ser amplamente descentralizada.

$[\ldots]$

Capítulo IV

\section{DA DELEGAÇÃO DE COMPETÊNCIA}

Art. 11. A delegação de competência será utilizada como instrumento de descentralização administrativa, com o objetivo de assegurar maior rapidez e objetividade às decisões, situando-as na proximidade dos fatos, pessoas ou problemas a atender.

Não obstante a vigência atual do texto mencionado, frise-se, mais uma vez, que as intenções modernizadoras seguiram ao lado da conservação de práticas já sedimentadas na cultura política brasileira. Aos cargos de maior responsabilidade foram designados membros do poder executivo, em lugar da implantação de planos de cargos e carreiras para administradores públicos de alto nível. ${ }^{38}$ Esse fato não se mostra novo, em razão das circunstâncias históricas já abordadas até aqui. Também não se confirma em novidade o fato de, após expostas à sociedade as intenções do Estado através do PDRAE, em 1995, não haver a distribuição dos direitos sociais potencialmente adquiridos após a promulgação da Constituição de

\footnotetext{
${ }^{38}$ Prosseguem os autores do PDRAE em suas críticas: O núcleo burocrático foi, na verdade, enfraquecido indevidamente através de uma estratégia oportunista do regime militar, que não desenvolveu carreiras de administradores públicos de alto nível, preferindo, ao invés, contratar os escalões superiores da administração através das empresas estatais. Em meados dos anos 70, uma nova iniciativa modernizadora da administração pública teve início, com a criação da SEMOR - Secretaria da Modernização. Reuniu-se em torno dela um grupo de jovens administradores públicos, muitos deles com formação em nível de pós-graduação no exterior, que buscou implantar novas técnicas de gestão, e particularmente de administração de recursos humanos, na administração pública federal. No início dos anos 80 , registrou-se uma nova tentativa de reformar a burocracia e orientá-la na direção da administração pública gerencial, com a criação do Ministério da Desburocratização e do Programa Nacional de Desburocratização (PrND), cujos objetivos eram a revitalização e agilização das organizações do Estado, a descentralização da autoridade, a melhoria e simplificação dos processos administrativos e a promoção da eficiência. As ações do PrND voltaram-se inicialmente para o combate à burocratização dos procedimentos. Posteriormente, foram dirigidas para o desenvolvimento do Programa Nacional de Desestatização, num esforço para conter os excessos da expansão da administração descentralizada, estimulada pelo Decreto-Lei 200/67. (grifo nosso).
}

1988. Se considerados os direitos sociais, a assistência social, saúde e educação como direitos fundamentais (cap. II), não é cabível transferir à população a consecução das circunstâncias mínimas materialmente necessárias à realização pessoal do indivíduo. Ratificar esta medida dentro de um plano de Estado é transferir aos cidadãos toda a responsabilidade pela sua própria sobrevivência na coletividade. Algo que não se coaduna com a participação e valorização do poder central no curso do processo sóciopolítico nacional.

Considerando eventual necessidade e correição da ideia adotada pelo PDRAE, a solicitação indiretamente feita à sociedade civil importa, para seu sucesso, educação sobre a ideia de participação e cidadania, algo que não ocorreu nos últimos séculos, bem como efetivo compromisso planejado de parceria do Estado com seus subordinados, situação que não se mostra evidente no Plano Diretor de Reforma do Aparelho Estatal. A demanda oferecida à sociedade civil corresponde aos serviços estatais não exclusivos. Estes integram, na visão dos redatores do plano, o setor onde o Estado atua simultaneamente com outras organizações públicas não estatais e privadas.

\begin{abstract}
As instituições desse setor não possuem o poder de Estado. Este, entretanto, está presente porque os serviços envolvem direitos humanos fundamentais, como os da educação e da saúde, ou porque possuem 'economias externas' relevantes, na medida em que produzem ganhos que não podem ser apropriados por esses serviços através do mercado. As economias produzidas imediatamente se espalham para o resto da sociedade, não podendo ser transformadas em lucros. São exemplos deste setor: as universidades, os hospitais, os centros de pesquisa e os museus ${ }^{39}$ (grifo nosso).
\end{abstract}

Em contrapartida, os serviços considerados exclusivos e estratégicos encerram-se em atividades de caráter mais objetivo, tais como a cobrança e fiscalização dos impostos, a polícia, a previdência social básica, o serviço de desemprego, a fiscalização do cumprimento de normas sanitárias, o serviço de trânsito, a compra de serviços de saúde pelo Estado, o controle do meio ambiente, o subsídio à educação básica, o serviço de emissão de passaportes

${ }^{39}$ PDRAE, 1995, p. 40-41. 
e planejamento e formulação das políticas públicas, respectivamente. $^{40}$

Já fora evidenciado que a efetivação dos direitos fundamentais, na visão dogmática e jurisprudencial predominantes, importa a observância do respeito ao princípio da dignidade da pessoa humana, elemento de maior relevância das sociedades democráticas contemporâneas após a segunda guerra mundial. ${ }^{41}$ Não parece razoável que o substrato filosófico de parte significativa dos Estados Contemporâneos seja relativizado da maneira como se afigura. Sugere até mesmo um contrassenso que direitos declaradamente fundamentais se agrupem na categoria de serviços não exclusivos e estejam deslocados do núcleo estratégico do Estado, pois, em última análise, a promoção da justiça social e a dignidade da pessoa humana se conformam em estratégia de governo, simultaneamente motivo e consequência das políticas públicas e ações governamentais de variada sorte.

Seguindo esse raciocino, a igualdade vislumbrada pela teoria de Thomas H. Marshall encontra na fruição das condições materiais mínimas de realização pessoal, ou mínimo existencial, questão fundamental à redução das desigualdades proporcionadas pelo sistema econômico vigente. Segundo Falbo, a cidadania, indo além do status juridicamente atribuído via preenchimento de requisitos preestabelecidos legalmente, atua como "[...] meio

${ }^{40} \mathrm{Na}$ divisão de setores estabelecida pelo PDRAE, registra-se, ainda o setor de Produção de Bens e Serviços para o Mercado, caracterizado por ser a área de atuação das empresas. É caracterizado pelas atividades econômicas voltadas para o lucro que ainda permanecem no aparelho do Estado como, por exemplo, as do setor de infraestrutura. Estão no Estado seja porque faltou capital ao setor privado para realizar o investimento, seja porque são atividades naturalmente monopolistas, nas quais o controle via mercado não é possível, tornando-se necessário no caso de privatização, a regulamentação rígida.

${ }^{41}$ Quanto a este ponto, é importante evidenciar a qualidade aberta da expressão, fato que não lhe confere unanimidade. Isto porque, nos últimos anos, a evolução dos trabalhos em direito, tanto teóricos quanto doutrinários, busca ora problematizar, merecidamente, os discursos pautados na dignidade da pessoa humana, quanto impor limitações ao alargamento interpretativo que a corrente principiológica via ponderação proporciona ao aplicador do direito. Não por acaso, esses são os casos de trabalhos versando sobre as limitações aos direitos fundamentais, notadamente na seara do direito constitucional. Contudo, por se tratar de uma obra ilustrada pelo confronto entre normas atinentes à Reforma do Aparelho do Estado brasileiro e os preceitos inaugurados pela Constituição de 1988, firma-se a opção pela doutrina constitucional majoritária. de integração social, diante das desigualdades do mercado e assim, serve também às economias de mercado." ${ }^{42}$ O responsável, pois, em fornecer tais condições é o Estado, o sistema executivo, mediante o sistema de educação e serviços sociais, os quais integram o artigo sexto da Constituição de 1988.

Infere-se do quadro exposto que o Estado em crise a ser reformado é um Estado constitucional ${ }^{43}$ e, no caso brasileiro, de forte significado social. Os direitos fundamentais, desse modo, ocupam lugar central na condução do sistema jurídico, ora servindo de base hermenêutica para subsunção do fato à norma jurídica, ora confirmando-se como direito subjetivo, passível de tutela jurisdicional. ${ }^{44}$ Portanto, no processo de reforma do Estado, a posição preferencial dos direitos fundamentais deve ser respeitada e as funções desses direitos potencializadas. A reforma do Estado deve servir, outrossim, para elevar o patamar civilizatório e não para reduzi-lo ou fragilizá-lo. ${ }^{45}$

O número cada vez maior de associações civis deve ser observado sob uma óptica crítica da necessidade e do incentivo promovido pelo governo. Não parece razoável imprimir à sociedade uma vocação solidária quando o curso da história se mostra favorável ao uso pessoal do patrimônio público, ao patrimonialismo, ao estamento burocrático. Contudo, isso não significa que as entidades de prestações de serviços sociais tenham alcançado convívio com a sociedade somente nas últimas décadas. A filantropia sempre esteve presente em território nacional desde a colonização, na figura da Igreja Católica e suas ordenações. Estas ainda se mantêm, mas dividindo espaço com Organizações Sociais Civis DE Interesse Público (OSCIPS), Organizações Sociais (OS) e Organizações Não Governamentais (ONGs) da mais variada sorte, atingindo aos mais variados públicos.

${ }^{42}$ FALBO, Ricardo Nery. Cidadania e violência no judiciário brasileiro: uma análise da liberdade individual. Porto Alegre: S. A. Fabris Editor, 2002. p. 98

${ }^{43}$ STEINMETZ, Wilson. Premissas para uma adequada reforma do Estado. Revista Eletrônica sobre a Reforma do Estado (RERE), Salvador, n. 14, jun./ago. 2008. Disponível: http:// www.direitodoestado.com.br/redae.asp. Acesso em 11 de maio de 2009.

${ }^{44}$ BARROSO, Luis Roberto. O direito constitucional e a efetividade de suas normas. 7. ed. Rio de Janeiro: Renovar, 2003. p. 145.

${ }^{45}$ BARROSO, Luis Roberto. O direito constitucional e a efetividade de suas normas. 7. ed. Rio de Janeiro: Renovar, 2003. p. 145. 
Nas últimas duas décadas, a publicização difundida pela Reforma Administrativa importou um movimento de terceirização das políticas públicas, acarretando consequente configuração do campo associativo brasileiro, como se este fosse um conjunto de prestadores de serviço do Estado, contribuindo, teoricamente, para aumentar a eficiência e reduzir o custo de implementação das ações públicas sociais. ${ }^{46} \mathrm{~A}$ desresponsabilização do Estado face às suas atribuições originárias é íntima do cenário brasileiro, haja vista a relação estabelecida entre aquele e as entidades de apoio à saúde, assistência social e educação, ligadas à igreja católica durante séculos. O conjunto de tais associações ou "entidades filantrópicas" permanece nos dias atuais sob a forma de Universidades Católicas, Santas Casas de Misericórdia, orfanatos, asilos, obras de caridade. $\mathrm{O}$ arcabouço jurídico que vincula essas instituições e o Estado, principalmente no que se refere ao repasse de recursos públicos, serve como apoio institucional para a compreensão e crítica do atual fenômeno em exame.

De acordo com Jorge Eduardo Durão e Leilah Landim:

[...] a aliança entre fé e Pátria, entre a poderosa Igreja Católica e o governo populista e ditatorial de Getúlio Vargas (1930-1945), foi o pano de fundo para o repasse de recursos públicos às escola, hospitais e obras sociais católicas espalhadas pelo país. Não é, portanto, por acaso que data desse período a espinha dorsal da legislação, mantida até hoje, que regula as relações entre Estado e organizações privadas sem fins lucrativos. Ou seja, a centralização e a provisão direta de serviços pelo Estado na área da educação, saúde e assistência não deixou de reservar um lugar para as organizações privadas sem fins lucrativos. $^{47}$

A reprovação no âmbito jurisdicional ao que Carlos Montaño denomina desresponsabilização do Estado no trato da "questão social"\$8 encontra respaldo na tese de Orivaldo Leme Biagi. Segundo o autor, os proble-

\footnotetext{
${ }^{46}$ ASSOCIAÇÃO BRASILEIRA DE ONGS. Um novo marco legal para as ONGS no Brasil: fortalecendo a cidadania e a participação democrática. São Paulo: ABONG, 2005.

${ }^{47}$ ASSOCIAÇÃO BRASILEIRA DE ONGS. Um novo marco legal para as ONGS no Brasil: fortalecendo a cidadania e a participação democrática. São Paulo: ABONG, 2005. p. 110.

${ }^{48}$ MONTAÑO, Carlos. Políticas sociais estatais e "Terceiro Setor": O projeto Neoliberal para a atual resposta à "Questão Social”.I Coloquio Brasil/Uruguay: "Questão urbana, políticas sociais e serviço social”. Escola de Serviço Social - UFRJ. Rio de Janeiro, 11-12, Abril 2002.
}

mas encontrados na legislação atinente ao terceiro setor resultam de questão comum a toda a estrutura jurídica brasileira, qual seja, sua qualidade excessivamente burocrática, utilizada como mecanismo de controle ou instrumentalização da sociedade em nome dos interesses dos setores governamental e mercantil, ${ }^{49}$ numa extensão, para a atualidade, do modelo de estamento burocrático elaborado por Raymundo Faoro.

Dessa forma, fica a expectativa de melhorias, as quais devem acontecer paulatinamente e de maneira global, priorizando-se campos onde a sociedade possa refletir acerca de seu próprio comportamento. Isto se dá por meio da educação. Educação que deverá formar cidadãos, pessoas aptas a pensar sobre seus direitos e obrigações, sobre, inclusive, os meios de comando aos quais estão submetidas e a escala de cumprimento de seus deveres, escapando, dessa forma, da cidadania meramente formal e tornando efetiva a noção de cidadania participativa tão cara à nossa vigente Carta Constitucional.

\section{Conclusão}

No Brasil, o marco legal que instaurou a transferência das funções estatais para o chamado Terceiro Setor foi o Plano Nacional de Desestatização de 1990, ratificado como programa de estado, em 1995, por meio do Plano de Reforma do Aparelho Estatal. Os mesmos objetivavam traçar um novo paradigma de administração pública gerencial, com ênfase no controle de resultados, em detrimento do excessivo burocratismo que provocara um inchaço da máquina administrativa, colaborando para o desencadeamento da chamada crise fiscal, em fins da década de 1970 .

Desde logo pode-se observar que, enquanto manifestação da sociedade civil, o advento e a proliferação de iniciativas privadas visando à prestação, sobretudo de serviços sociais, não pode ser tratada de modo isolado, fruto apenas das últimas décadas. Foi necessário adentrar na história política e social dos Estados, dedicando especial atenção ao contexto brasileiro.

\footnotetext{
${ }^{49}$ BIAGI, Orivaldo Leme. Discussões sobre o Ordenamento Jurídico do Terceiro Setor na Legislação Brasileira. In: BROWN, Ellis Wayne. (Org.). O terceiro setor em perspectiva: Constituição, Interfaces e Operacionalização - A Organização Social Tripartite. São Paulo: Atibaia, p.123.
} 
Os estudos dedicados tanto à sociedade civil quanto à cidadania sempre tiveram como base de apoio as transformações econômicas e políticas que cercaram o mundo. A questão temporal da matéria é bastante ampla. Entretanto, ao optar pela dinâmica social presente no século XX, tem-se como ponto inaugural das crises exploradas a busca de soluções aos problemas decorrentes das lacunas do Liberalismo clássico. Permaneceu o Brasil assentado no patrimonialismo, quando o mundo liberal acenava para a transmigração do capitalismo político para o capitalismo moderno, quando o súdito cede lugar ao cidadão e o Estado, por conseguinte, assume o papel de garantidor da autonomia do homem livre.

Quando a livre iniciativa e a mão livre do Estado manifestaram mais defeitos do que qualidades, fora preciso uma nova forma de intervenção estatal. Deu-se, então, a implementação do Estado Social-Burocrático, com a ilusão de economia próspera e melhorias infindáveis da qualidade de vida da população. O Brasil, neste período, assistiu com entusiasmo ao milagre econômico, o qual, em suas entrelinhas, sustentava significativa redução de direitos políticos e civis através do autoritarismo da ditadura militar. O intervencionismo estatal não solucionou os problemas tipicamente liberais. Ao contrário. Quando da redação do Plano Diretor de Reforma do Aparelho Estatal, muitos dos argumentos foram direcionados à forma incipiente como o Estado administrou tanto a economia como a prestação dos serviços públicos. Nem a Constituição Federal de 1988 escapou das avaliações negativas.

A atual conjuntura brasileira encontra críticos e adeptos. Alguns, como o ex-Ministro Luiz Carlos Bresser-Pereira, veem na incorporação de serviços não exclusivos do Estado pela sociedade civil um caminho para a real eficácia de serviços inseridos no elenco constitucional de direitos fundamentais. Em outra linha de raciocínio, adotada pelo professor Carlos Montaño, a atual fase de desresponsabilização do Estado é uma medida equivocada de imprimir ao indivíduo a tarefa de atingir os meios materiais minimamente necessários para suas realizações pessoais. Frise-se, ainda, que o documento que formaliza a reorganização administrativa do Estado Brasileiro, PDRAE, apenas indicou tarefas à sociedade civil, mediante a criação de organizações sociais, regulamentadas por lei, sem, contudo, imputar a si mesmo obrigações para auxiliar na prestação de serviços públicos historicamente de responsabilidade estatal.
As críticas são pertinentes e conservam a intenção de melhorar as leis que definem as modalidades e títulos das organizações civis sem fins lucrativos, as populares ONGs. Não há como negar que as regras em vigor apresentam caminhos que permitem abusos ou desvio de objeto a administradores de má fé.

Além disso, não obstante a nítida progressão do período em que as constituições restavam condicionadas à prevalência dos interesses estatais, reduzidas a escritos nominais sem correspondência e valor normativo com o mundo que regem, para a época do constitucionalismo moderno, da eficácia das normas constitucionais dotadas de exigibilidade jurídica, o clientelismo ainda colhe os frutos das raízes plantadas na segunda metade do século XIX. Desse modo, observa-se que ainda impera a política do "você sabe com quem está falando?", pautada no favorecimento pessoal, a qual gera na população maior expectativa de ver seus direitos assegurados do que os dispositivos da Carta Constitucional em vigor.

Ademais, objetivando ampliar a visão do tema em estudo, deve-se ter em mente que as normas atinentes às Organizações Sociais Sem Fins Lucrativos tentam acompanhar a evolução da sociedade civil, ou seja, os fatos se antecipam às leis. $\mathrm{E}$ os fatos, nos ensina a nossa genealogia, não podem ser tratados isoladamente. Antes de recriminar, de tentar moralizar e prestar satisfações às pressas a quem se está representando, é preciso analisar a fundo o exato papel que cumprem as ONGs, onde e por que praticam seu objeto. É sempre bom frisar que as críticas em relação ao conjunto de normas vigentes parte não apenas dos algozes, mas daqueles que defendem, vivem e são incentivados por estas organizações.

\section{Referências}

ASSOCIAÇÃO BRASILEIRA DE ONGS. Um novo marco legal para as ONGs no Brasil: fortalecendo a cidadania e a participação democrática. São Paulo: ABONG, 2005.

BARROSO, Luis Roberto. O Direito constitucional e a efetividade de suas normas. 7. ed. Rio de Janeiro: Renovar, 2003.

BAZILLI, Roberto Ribeiro. Organizações da sociedade civil de interesse público: nova modalidade de parceria. Revista dos Tribunais, São Paulo, v. 779, p. 79-92, set. 2000 . 
BIAGI, Orivaldo Leme. Discussões sobre o ordenamento jurídico do terceiro setor na legislação brasileira. In: BROWN, Ellis Wayne. (Org.). O terceiro setor em perspectiva: constituição, interfaces e operacionalização A organização social tripartite. São Paulo: Atibaia, 2006. v. 1, p. 179-203.

BRASIL. Plano diretor de reforma do aparelho do estado - PDRAE. Disponível em: <http://www.planalto.gov.br/ publi_04/colecao/plandi.htm>. Acesso em: 15 maio 2009.

BRESSER-PEREIRA, Luiz Carlos; NURIA Cunill Grau. Entre o Estado e o mercado: o público não-estatal. In: BRESSER-PEREIRA, L. C.; Nuria Cunill Grau (Org.), O público não-estatal na reforma do estado. Rio de Janeiro: FGV, 1999.

BRESSER-PEREIRA, Luiz Carlos. Sociedade Civil: sua democratização para a reforma do Estado. In: BRESSERPEREIRA, Luis Carlos; WILHEIM, Jorge; SOLA, Lourdes (Org). Sociedade e estado em Transformação. São Paulo: UNESP/ENAP, 1999. p. 67-116.

BRESSER-PEREIRA, Luiz Carlos. Uma interpretação da América Latina: a crise do Estado. Novos Estudos CBRAP, São Paulo, 37, p. 37-57, nov. 2003.

FALBO, Ricardo Nery. Cidadania e violência no judiciário brasileiro: uma análise da liberdade individual. Porto Alegre: S. A. Fabris, 2002.

FALCÃO, Joaquim. Democracia, direito e terceiro setor. 2. ed. Rio de Janeiro: FGV, 2006.

FAORO, Raymundo. Os donos do poder: formação do patronato político brasileiro. 3. ed. São Paulo: Globo, 2001.

HOBSBAWN. Eric. A era dos extremos: o breve século XX 1914-1991. 2. ed. São Paulo: Companhia das Letras, 2002.
JUCÁ, Maria Carolina Miranda. Crise e reforma do Estado: as bases estruturantes do novo modelo. Jus Navigandi, Teresina, ano 7, n. 61, jan. 2003. Disponível em: <http://jus2.uol.com.br/doutrina/texto.asp?id=3598>. Acesso em: 15 maio 2009.

LEME, Alessandro André. Globalização e reformas liberalizantes: contradições na reestruturação do setor elétrico brasileiro nos anos 1990. Revista de Sociologia e Política, Curitiba, v. 25, p.171-192, 2002.

MARTINS, Marcos Francisco. Uma "catarsis" no conceito de cidadania: do cidadão cliente à cidadania com valor ético-político. Revista de Ética, Campinas, v. 2, n 2, p. 106-118, jul. 2000.

MASSAÚ, Guilherme Camargo. A Sociedade do momentâneo: a impossibilidade de fuga para o futuro e o reflexo na senda jurídica. Revista Sociologia Jurídica, n. 4, Jan./Jun. 2007.

MIRANDA, Jorge. Teoria do Estado e da Constituição. Rio de Janeiro: Forense, 2005.

MONTAÑO, Carlos. Políticas sociais estatais e "Terceiro Setor": O projeto Neoliberal para a atual resposta à "Questão Social”.I Coquio Brasil/Uruguay: "Questão urbana, políticas sociais e serviço social". Escola de Serviço Social - UFRJ. Rio de Janeiro, 11-12 Abril 2002.

MONTAÑO, Carlos. Terceiro setor e questão social: crítica ao padrão emergente de intervenção social. 4. ed. São Paulo: Cortez, 2007.

STEINMETZ, Wilson. Premissas para uma adequada reforma do Estado. Revista Eletrônica sobre a Reforma do Estado (RERE), Salvador, Instituto Brasileiro de Direito Público, n. 14, jun./ago. 2008. Disponível em: <http:// www.direitodoestado.com.br/redae.asp $>$. Acesso em: 11 maio 2009. 
Para publicar na revista Brasileira de Políticas Públicas, acesse 0 endereço eletrônico www.publicacoesacademicas.uniceub.br. Observe as normas de publicação, para facilitar e agilizar o trabalho de edição. 